\title{
Estimation of tensile mechanical parameters of existing masonry through the analysis of the collapse of Volterra's urban walls
}

\author{
Mario Lucio Puppio, Linda Giresini \\ University of PIS A, Italy \\ mariolucio.puppio@ing.unipi.it, linda.giresini@unipi.it
}

\begin{abstract}
In this work, numerical analyses on the Volterra's ancient walls are performed to understand the causes of a collapse occurred after an extreme rainfall (2014) and to identify the mechanical parameters that most influenced it. The stretch of collapsed wall is modelled with finite elements by distinguishing the material composing the multi-leaf wall. Non-linear static analyses are carried out with the DIANA software considering different levels of hydraulic head up to reach the collapse of the structure. The impact on the failure modes of the involved parameters, such as tensile strength, fracture energy and shear strength, are discussed. Tensile strength is found as the most relevant parameter in the failure mode. Finally, a 3-dim model is presented, and the results show a very good agreement with the failure mode actually occurred in terms of both failure modes and displacement fields. The safety evaluation is performed in the as-built and the retrofitted configuration, consisting in the wall restrained by tie-rods. The results show a significant increasing of the safety level of the retrofitted configuration showing a considerable improvement not only in terms of limit equilibrium but also in terms of structural capacity of the wall.
\end{abstract}

KEYWORDS. Historic masonry walls; DIANA; Non-linear analysis; Vulnerability analysis; Fracture energy; Tensile strength.

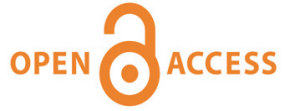

Citation: Puppio, M. L., Giresini, L., Estimation of tensile mechanical parameters of existing masonry through the analysis of the collapse of Volterra's urban walls, Frattura ed Integrità Strutturale, 49 (2019) 725-738.

Received: 02.05.2019

Accepted: 10.06.2019

Published: 01.07.2019

Copyright: (C) 2019 This is an open access article under the terms of the CC-BY 4.0, which permits unrestricted use, distribution, and reproduction in any medium, provided the original author and source are credited.

\section{INTRODUCTION}

$\mathrm{T}$ he safety assessment of historic constructions is a relevant objective to be pursued by researchers devoted to the conservation of the cultural heritage. In particular, masonry structures not designed to withstand different types of accidental actions (such as earthquakes, flood events, fire, etc.) should be carefully analyzed and retrofitted in the case proper safety levels are not guaranteed. For generic masonry structures traditional (tie-rods) and modern (FRP) $[1,2]$ 
techniques can be used. In particular, out-of-plane modes represent the most vulnerable modes, regardless of the applied load, and therefore they should be analyzed with proper modelling approaches (kinematic [3-5], finite element [6-8] and rocking [9] analyses). A particular class of historic constructions are the masonry urban walls acting as defense system of the inner historic town. Their vulnerability to external actions, such as the degradation and flood events, needs to be properly considered. Several researchers analyzed collapses occurred to this typology of masonry structures [10] and analyzed retrofitting techniques to guarantee adequate safety levels [11,12].

This paper illustrates the numerical modelling of a stretch of urban walls in the well-known Volterra town located in Tuscany (Italy). The flood scenarios are here examined, in particular the effect of a monotonically increasing thrust due to water on the upstream wall section. A first purpose is to identify mechanical parameters of the historic masonry by considering the collapse of the walls occurred in 2014 after an extreme rainfall event. The structural features of the wall and the collapse are described in Section 3. The most important aspects related to the stability of retaining walls is illustrated in the Section 3, whereas Section 4 presents the methodology adopted to estimate the mechanical parameters and to simulate the effects of the flood on the walls. Section 5 includes the assumptions, the method and the results of the model in the as-built state, whereas the retrofitted state is discussed in Section 6. The last Section contains the results of simplified analyses on a 3-dim model of the historic walls $[13,14]$.

\section{THE VOLTERRA'S URBAN WALLS: DESCRIPTION AND COLLAPSE}

$\mathrm{V}$

olterra is a walled mountaintop town in Tuscany (Italy), with structures from the Etruscan, Roman, and Medieval periods. The city walls are a remarkable Etruscan work that was gradually modified over the centuries. The primitive walls were built on IV century BC and remained intact up to the High Middle Ages, when the municipality decided to build a new defense system. The ancient walls measure $7 \mathrm{~km}$ whereas the actual medieval walls measure only $2.6 \mathrm{~km}$, encompassing an area of 26 hectares.

The main building material is the panchino, a stone typical of the west Tuscany region, fine grained and white sandstone, easily workable and porous. It normally acquires hardness and strength with prolonged exposure to external factors and demonstrated to be durable.

On January, 31st 2014, after that an extreme rainfall occurred, 30 meters of the urban walls collapsed (Fig. 1a) during the night. Luckily, there were no casualties, and the building close to the wall (at a distance of few meters) was not damaged at all. The part of collapsed walls is located between Porta all'Arco and Piazza dei Fornelli, one of the most panoramic points of the town. The collapsed wall is dated back to the second half of the XIII century and differs in technical features from the Etruscan walls, being mainly characterized by smaller blocks (Fig. 1b).

The collapsed portion of the wall can be defined as a retaining wall, the back part is completely filled with soil and behaves as a retainer for the rear two/four-storey buildings (Fig. 1a).

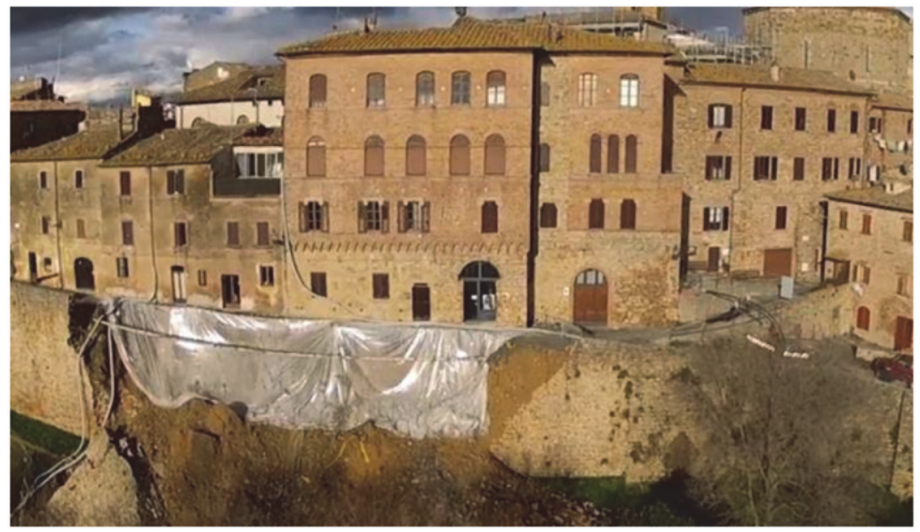

(a)

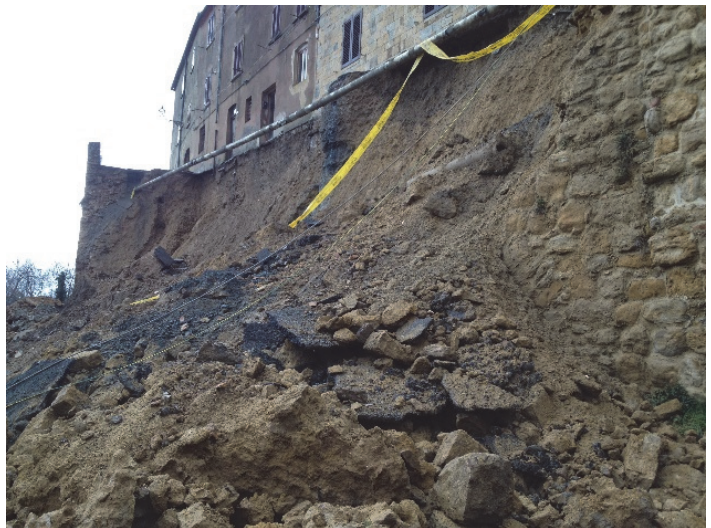

(b)

Figure 1: Historic urban walls of Volterra, the portion of wall right after the collapse (a) and the view from the base of the walls (b). In the background of figure (b) is also possible to see the typical section of the Urban walls of Volterra. 


\section{Causes of the collapse}

The causes of the collapse are multiple and of complex interpretation. It is necessary to observe that, as documents demonstrated (Fig. 2a), even in the early 20th century the stretch of wall under examination was highly vulnerable. The picture clearly shows a different masonry texture (Fig. 2), probably due to previous partial collapses and reconstruction. In addition, the moisture content, visible before collapse (Fig. 2) and proved by the presence of local vegetation, could have played a crucial role over time. This effect was likely exacerbated after the extreme event of rainfalls occurred during the days preceding the collapse. No proper drainage holes were visible in the collapsed part. The lack of a drainage system (or a non-adequate system) behind the wall probably caused filtration motions behind the retaining wall. This phenomenon plays a crucial role in the stability of a retaining wall, as it will be discussed in the third section ("Stability of masonry retaining wall"). The filtration phenomenon could have determined stresses not allowable for masonry, leading to its failure.

Also, the evidence of pipes (Fig. 2c) for water and gas services could have jeopardized the stability of the wall by reducing its resistance. However, the consequences could have been sensitively worse, due to the proximity of the buildings. It is worthy to observe that the landslide slope reached the foot of the rear structures (Fig. 2c), which surprisingly not only did not collapse, but also were not even damaged. The reason is perhaps due to the fact that part of the foundations is made of the ancient Etruscan walls, whose presence is proved by the pictures taken during the reconstruction (Fig. 2d) and by the results of standard penetration tests carried out for the soil identification.

Possible consolidation strategies to increase the safety level of this structure are related to an efficient drainage system, a global reinforcement of the stretch of wall through tie-rods avoiding out of plane mechanisms and surface coating of the wall front face to limit the detachment of stones.

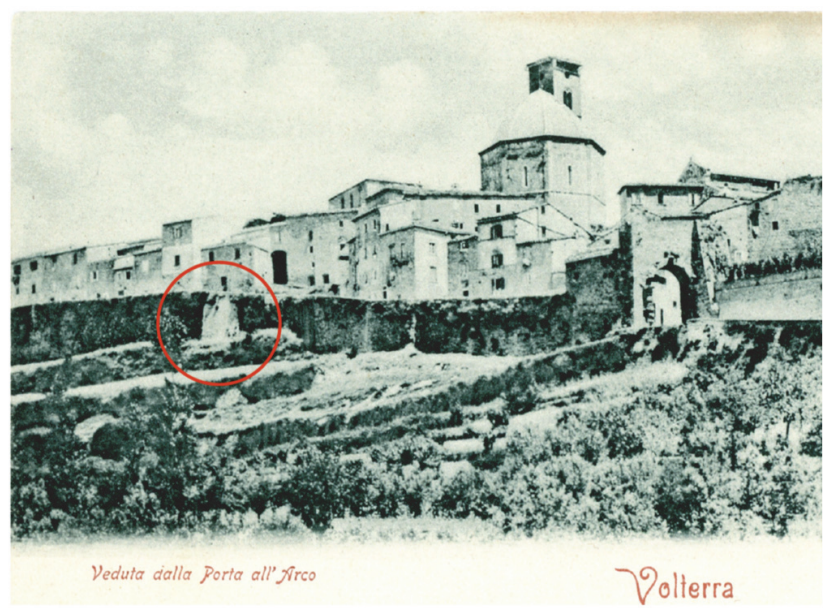

(a)

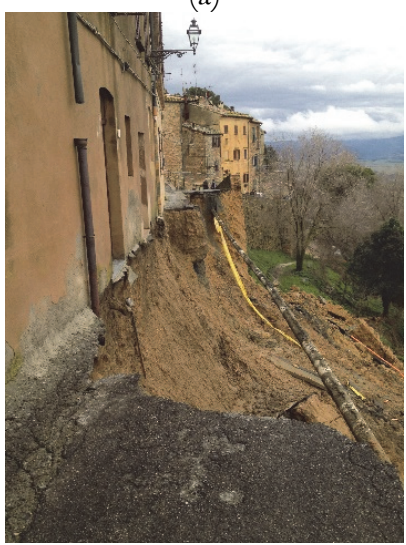

(c)

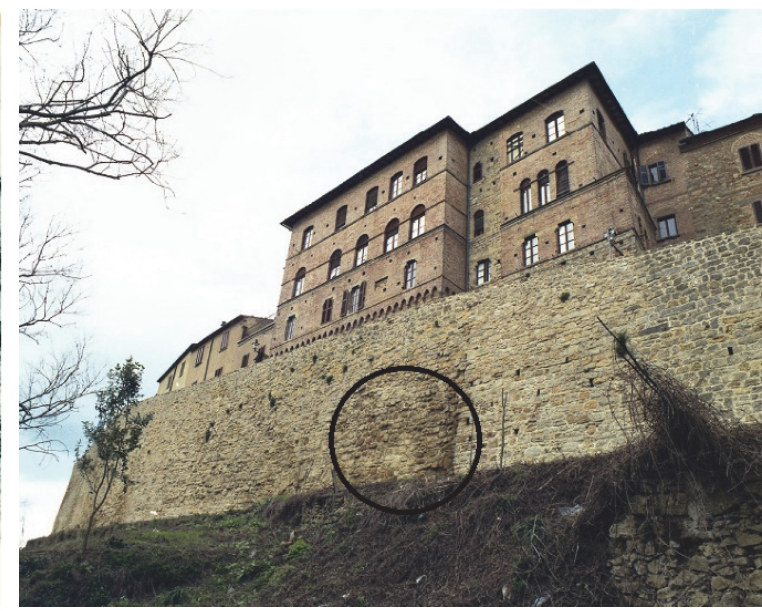

(b)

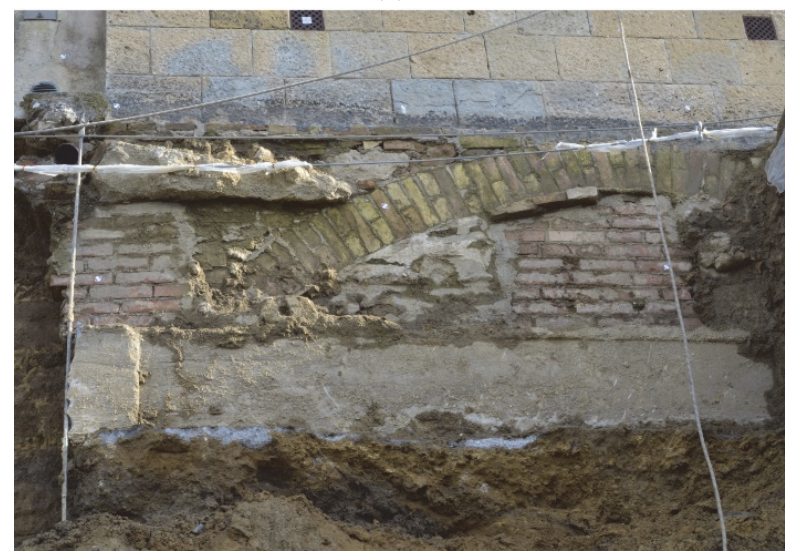

(d)

Figure 2: Picture of the wall in the early 20th century (a), moisture evidence (b), top-down view of the collapsed zone that shows the presence of pipes (c), down-top view of the collapsed zone that highlights the texture of the existing foundation of the buildings (d). 
Geometrical and mechanical features of the walls

The Volterra's historic Walls tend to show a variety of different styles. However, the collapsed wall section can be considered sufficiently homogeneous; the cross-section, evaluated through visual inspections after the collapse and check of original drawings, is shown in Fig. 3. The structure is $9 \mathrm{~m}$ high, $3,6 \mathrm{~m}$ thick at the bottom and 2,3 $\mathrm{m}$ thick at the top, with an average slenderness of about 3 . The inclination of the internal wall $\left(10^{\circ}\right)$ is greater than that of the external one $\left(4,5^{\circ}\right)$. The external and the internal wall develop along all the height and turn out to be about $75 \mathrm{~cm}$ thick, keeping it constant from the base to the top. The base is constrained to the ground; indeed, it lays at a depth of about $90 \mathrm{~cm}$ with respect to the valley slope. This aspect certainly generates a minimum of soil passive thrust that helps to constrain the retaining wall at its base but there are many uncertainties due to this aspect in particular related to the downstream slope.

The wall is multi-leaf with two square stone external walls with fairly resistant lime mortar and a central filling core. This inner core has the only purpose of providing weight, and therefore stability, to the gravity wall, but it shows scarce traces of mortar, with a behaviour that is halfway between a poor masonry and a coarse-grained soil.

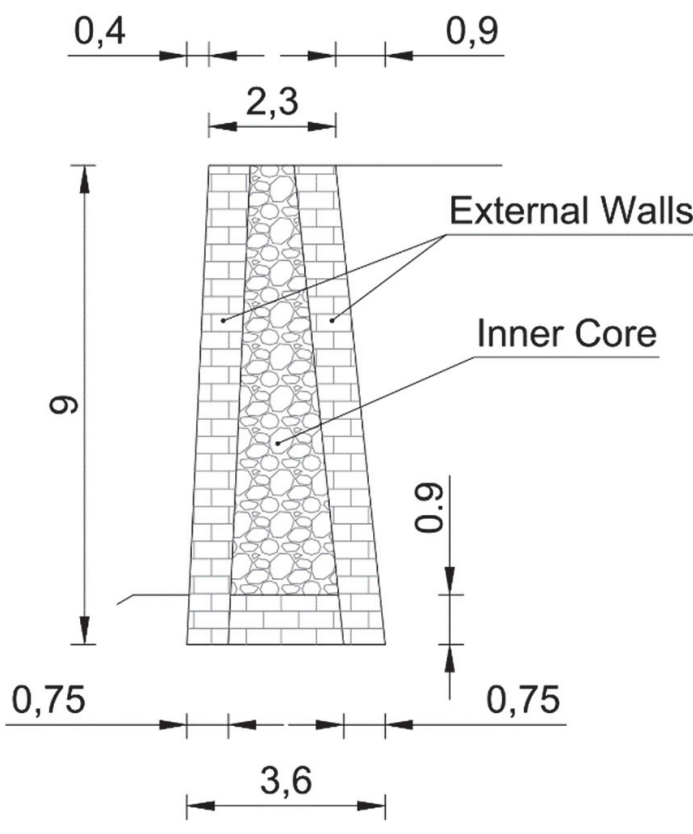

(a)

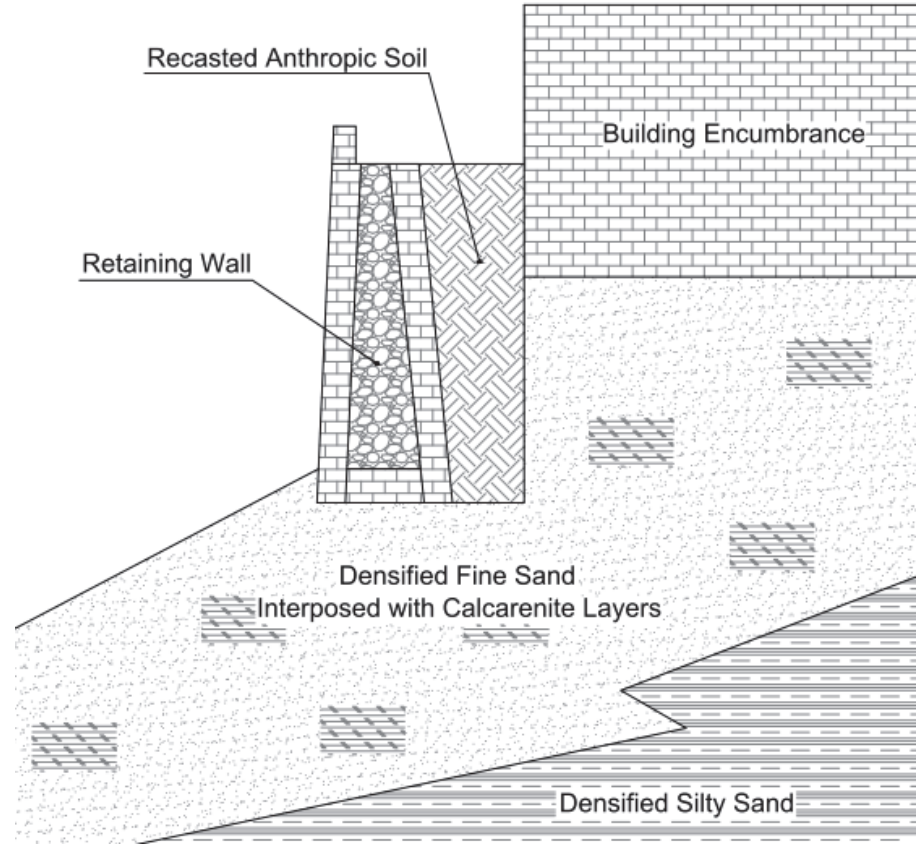

(b)

Figure 3: Wall structure with dimensions in $\mathrm{m}$ (a) and cross section view of the collapsed wall [12] (b).

The main problem in the collapse assessment is due to the fact that the material that makes up the masonry is strongly differentiated. Being an ancient wall, it is difficult to identify a precise masonry texture scheme. It follows that the material mechanical features are hardly identifiable, and it is only possible to make assumptions validated by the analysis of physical models [15]. Unfortunately, any experimental test on the remaining debris after the collapse was made to assess the mechanical properties of the wall. The method followed to perform the numerical analysis is expressed in the fourth Section ("Methodology for the estimation of wall mechanical parameters from numerical models").

\section{STABILITY OF MASONRY RETAINING WALLS}

he stability of a masonry retaining wall regards the stability of the system wall+backfill and that of the foundation. According to Chan [10], the stability of an old retaining wall is related to four parameters: (1) the retained soil strength, (2) the retaining wall geometry, (3) the slope inclination and (4) the groundwater level behind the wall. Among them, the soil resistance plays a non-fundamental role in the structural stability, with an incidence by only $10 \%$ in the studies performed by the cited author, whereas the main influence is given by the groundwater level and by the backfill 
inclination angle (for values greater than $30^{\circ}$ ). As for the geometry, the change in the front face slope does not affect so much the thickness required for the stability of the wall. By contrast, the change in the rear face slope influences the minimum value of safe thickness. If the rear face is inclined towards the backfill, sensitive improvements in stability are achieved and a wall can be thinner even with a small inclination. As recalled by Terzaghi and Coulomb and other Authors [16,17], cohesion play a relevant role in the stability, being that related to the shear failure. Indeed, the cohesion can be sufficient to guarantee the stability and can be found in in-situ decomposed materials and in a smaller amount in un-satured backfills, as a result of soil suction. This is usually the reason why some ancient masonry retaining walls stand with a relatively reduced width. However, cohesion could be strongly reduced by the soil saturation and therefore it is not recommended to rely on it if the backfill soil is liable to be saturated. The amount of friction at the back of a retaining wall depends on the downward displacement of the soil with the respect to the wall. Under ordinary circumstances, the friction angle existing between the wall and the retained soil $(\delta)$ varies between $2 / 3 \Phi$ and $\Phi[18,19]$.

\section{METHODOLOGY FOR THE ESTIMATION OF WALL MECHANICAL PARAMETERS FROM NUMERICAL MODELS}

A methodology in the assumption of constitutive laws and load scenarios is necessary to assess the mechanical parameters that played a relevant role in the collapse of the walls. Since the inner core of the wall is composed by rubble masonry (Fig. 3), it is complicated to identify realistic values of mechanical properties so that a homogenization process is needed to simplify the modelling, mediating the available notions interpolated by reports, pictures and historical documentation. The material of the wall is then considered as split into two homogenized materials, one for the external walls and another one for the inner core (Fig. 3a). The adopted process is that of trying to understand the parameters that most influence the masonry behavior from the results obtained from a physical model. Non-linear static analysis is carried out by evaluating the flood effects on the wall stability.

By evaluating the stress state found in relevant points of the structure and carrying out several parametric analyses, as a first starting point, the field of variable quantities are basically reduced to two main parameters: maximum tensile strength $f_{t}$ and maximum fracture energy $G_{f}$, which are crucial in the behaviour of historic masonry modelling $[6,20]$. Both these quantities are clearly linked to the masonry tensile strength behavior. It is indeed usually the tensile stress to determine the breakage of a brittle material such as masonry, even more in the presence of a rubble masonry, characterized by low values of tensile strength.

The first parameter $\left(f_{t}\right)$ characterizes the tensile yielding stress, to which a very reduced yield strain is associated, whereas the second one $\left(G_{f}\right)$ describes the plastic softening behaviour. The fracture energy is a function of the area subtended by the softening envelope of the tensile constitutive law. A linear softening branch is considered, in which the ratio $G_{f} / \mathrm{h}$ between fracture energy and fracture width $(b)$ represents the area under the constitutive law curve [6], and it is therefore closely related to the ultimate strain of the material. Once this point is attained, the material can be considered as broken and it is no longer able to withstand any additional stress. Hence, it is evident that, when these two quantities change, the retaining wall strength to the imposed loads varies and, as it will be shown later, also the collapse mechanism will be modified.

The main parameter considered is the ratio of the external wall tensile strength to the inner core tensile strength, initially taken equal to 2. This ratio is assumed by considering similar studies carried out on multi-leaves walls [21] and based on the report on the material drafted for the purposes of reconstruction [22,23], which highlights how the inner core presents few traces of mortar and binders. For this reason, the internal material behavior could be still more reduced, considering it as a permeable material and modelling it with the same mechanical features of a good gravelly soil. Hence, an analysis with a strength ratio equal to 4 is also performed. In the conclusion, the results of the analysis are presented and discussed, highlighting the contributions of the above-mentioned assumptions on the failure modes.

\section{NUMERICAL MODEL OF THE AS-BUILT WALL}

\section{Assumptions on modelling techniques and smeared crack model}

A mong the possible techniques available for modelling masonry, micro-modelling, simplified micro-modelling and macro-modelling, the latter is chosen for the case under examination. Indeed, the Volterra's walls show a complex texture, the units are irregular and masonry is difficult to be mechanically characterized, as discussed in the previous section. The objective of the numerical analysis is to describe the effect of external loads (flood event) on joints and units 
in a smeared sense. This leads to a composite model with anisotropic properties. This method is adequate when the dimensions of the finite element are large enough in comparison to the unit/block dimensions [24].

The Multi-Directional Fixed Crack (MDFC) model with damage and plasticity constitutive laws provided by the software DIANA FEA [25] are used. With this model, the cracking process is not represented by an actual detachment between elements of the same mesh, but it is obtained by smearing the damage on the finite element interested by the strain concentration, by degradation of mechanical properties of the elements involved. The MDFC model is based on the decomposition of the total strain into an elastic strain and a crack strain (Litton 1975), a criterion for crack initiation depending on a tension cut-off and a limit threshold angle between two consecutive cracks. The conventional cracking parameters are the reduction factor of the Young's modulus $\mu$ and the reduction factor on the shear modulus $\beta$ [26].

It is clear that such a modelling assumes for masonry an intermediate trend between the brittle and the plastic behaviour. This softening features has been defined by Lourenço [27] as a parabolic trend, but can be numerically described in several ways, the simplest of which is clearly that of a linear tension softening. In the case of the Volterra's walls, after a preliminary analysis with the linear softening branch, the Moelands and Reinhard model [28] is used (exponential trend), because it is better suited to the plastic and damage model proposed in [29]. As for the tensile behaviour, the most relevant in brittle material such as masonry, the post-peak response can be simulated by two parameters: the cracking energy $G_{f}$ and the fracture width $h$. The stresses are determined as a function of the strain in a coordinate system oriented in the cracking direction; the crack orientation was assumed to be fixed whereas for the shear behaviour it was taken into account considering it as damage based.

A crucial aspect considered in the modelling is the soil-structure interaction. As shown in (Fig. 3 - b), the walls lay on densified fine sand with calcarenite layers, whereas the backfill derives from anthropic modifications and it is therefore highly non-homogeneous. Thus, for it, laboratory tests are carried out obtaining the soil volume density $(\gamma)$, its friction angle $(\Phi)$, the transversal contraction coefficient $(v)$, the cohesion (c) and the edometric module (M0), where the test has inhibited transversal dilation. For modelling purposes, the normal elastic modulus (E), with free transversal dilatation, is necessary. This can be obtained directly from the edometric modulus from the expression [30]:

$$
E=E_{E d} \frac{(1+v)(1-2 v)}{1-v}
$$

Soil is modelled with a surface interface that is managed by setting specific material parameters related to Mohr-Coulomb law with zero dilatancy.

\begin{tabular}{ccc}
\hline Soil Parameters & Base Soil & Backfill Soil \\
$\mathrm{E}\left[\mathrm{kN} / \mathrm{m}^{2}\right]$ & 23400 & 16240 \\
$\mathrm{u}$ & 0.35 & 0.35 \\
Density $\left[\mathrm{T} / \mathrm{m}^{3}\right]$ & 2 & 1.9 \\
Porosity & 0.4 & 0.4 \\
Cohesion $\left[\mathrm{kN} / \mathrm{m}^{2}\right]$ & 8 & 8 \\
Friction Angle $\varphi[\mathrm{deg}]$ & 12 & 12 \\
Initial Stress $\mathrm{K}_{0}$ & 0.398 & 0.412 \\
\hline
\end{tabular}

Table 1: Soil mechanical parameters. [31]

\section{Adopted mechanical parameters}

As for the linear material properties a Young's modulus of $\mathrm{E}=1.2 \mathrm{E}+06\left[\mathrm{kN} / \mathrm{m}^{2}\right]$, a Poisson's Ratio of $\nu=0.2$ and a mass density of $\gamma=2.1\left[\mathrm{~T} / \mathrm{m}^{3}\right]$ are selected. For the masonry post-peak behaviour, it is basically impossible to define actual values of fracture energy, but some indications (although related to brick masonry) are given in [6]. In the parametric analyses, the ratio between the external walls strength and that of the inner core was kept constant and primarily equal to 0.5 , secondly to 0.25 . The following initial values are considered: tensile strength, $f_{t}=0.35 \mathrm{MPa}$, tensile fracture energy, $G_{f}=0.02$; compressive strength, $f_{c}=1.95 \mathrm{MPa}$. Different values of fracture energy are assumed, from $0.00075 \mathrm{kN} / \mathrm{m}$ to $0.03 \mathrm{kN} / \mathrm{m}$; 
for each value of fracture energy, the tensile strength of the external walls is varied from values close to zero to values approximately one tenth of the compressive strength. Totally, about 300 plane strain analyses are performed, discussing the collapse behaviour and the stress/strain outputs in the structural elements.

Two soil types are modelled, as shown in Fig. 4: the "backfill soil" and "base soil", with characteristics reported in Table 1. The inclination of the downstream slope is of $50 \%$ and the lower and external extremes have been bounded with external constraints that prevent the displacement of the soil points in the direction perpendicular to the identified boundary.

The elements of the retaining wall and the backfill soil are meshed with element size of about $25 \mathrm{~cm}$, so that each backfill layer could be divided into at least two parts (Fig. 4a); while for the foundations and the underlying soil a less accurate mesh is assumed, roughly doubled with respect to the former one. A significant portion of backfill soil is modelled. The backfill soil is divided into 18 layers of $50 \mathrm{~cm}$ each to faster define the change in water level, causing the variation of the constitutive laws of the backfill soil. The external nodes of the finite element are hinged.

\section{Non-linear static analysis and loading conditions}

A non-linear static is performed to evaluate how the mechanical parameters affect the failure modes under a water thrust simulating a flood event. A load step analysis allows to evaluate the specific strain pattern at each step, providing displacements induced by the specific load configuration that led to the collapse of the structure. The permanent loads are self-weight and overload given by the buildings (Fig. 4). However, the interest is mainly focused on the strains induced by the water (with level "h" in Fig. 4b) thrust acting on the wall, constituting the second load step. In that, also the extreme condition of maximum water level (completely embedded soil) is considered. Naturally, this means to take into account a reduced soil thrust, being the effective specific weight lower than the soil specific weight, in any case, obtaining a greater loading action.

In the analysis two types of non-linearities are considered: the physical and the geometrical ones. As for the physical nonlinearity, plasticity, creep, cracking, non-linear elasticity, the interface nonlinear behaviour, shrinkage and concentration effects are taken into account. While regarding geometric non-linearities, the second order effects $(p-\delta)$ are considered, contemplating the variation of the geometry over time and the greater stress state induced by the loads acting on the modified geometric configuration.

The used iteration method is the secant (Quasi-Newton) Broyden-Fletcher-Goldfarb-Shanno (BFGS) method [32], in which the first tangent is calculated by the previous iteration and the convergence norm chosen refers to the displacements, with a convergence tolerance of 0.01 [25].

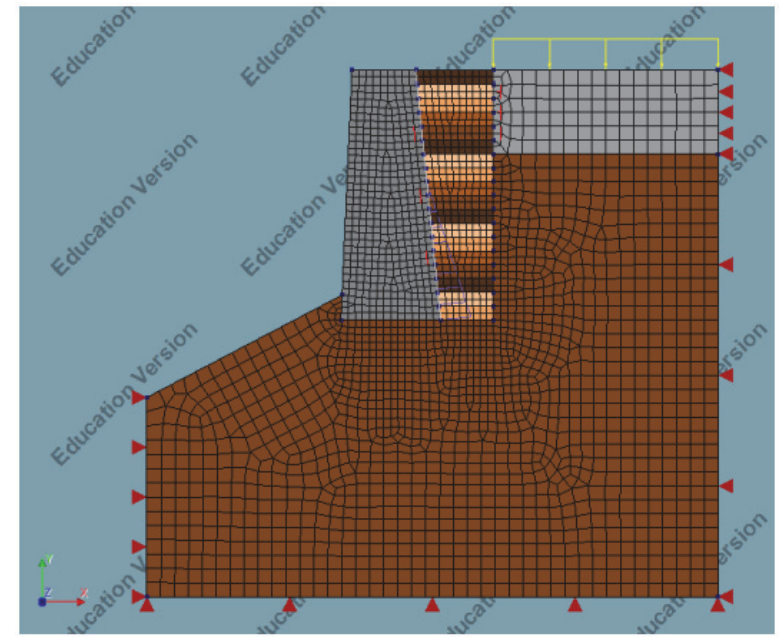

(a)

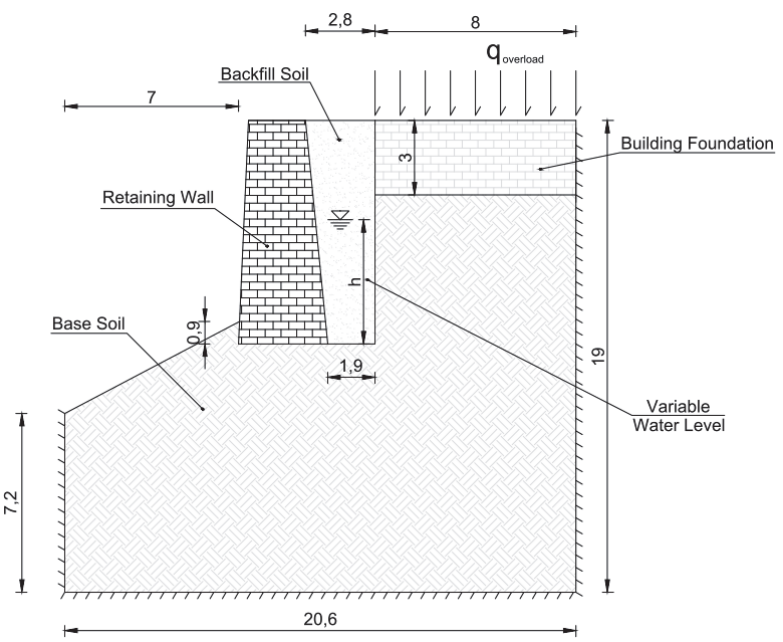

(b)

Figure 4: Finite element model in DIANA (a) and loading conditions in the plain strain analysis (b).

The considered loading conditions are self-weight, overload due to the back buildings and water thrust. The overload is assumed to be $10 \mathrm{kN} / \mathrm{m}^{2}$ per storey, therefore $40 \mathrm{kN} / \mathrm{m}^{2}$. The water pressure is considered as an external hydrostatic pressure acting on the internal edge of the retaining wall with variable value depending on the water level behind the wall. This loading condition is assumed to reproduce that occurred in the night when the collapse occurred. Indeed, it is likely 
that, due both to a lack of a proper drainage system behind the wall and to the heavy rainfall occurred on an already saturated soil, the hydraulic head gradually increased behind the wall, reaching a level able to cause the masonry failure. The water load was applied as small load steps, increasing the hydraulic head by $1 \mathrm{~cm}$ from one step to the next one.

Non-linear static analysis are carried out and results are showed in Fig. 5 considering the relative displacement of two control point placed at the bottom and at the top of the wall.

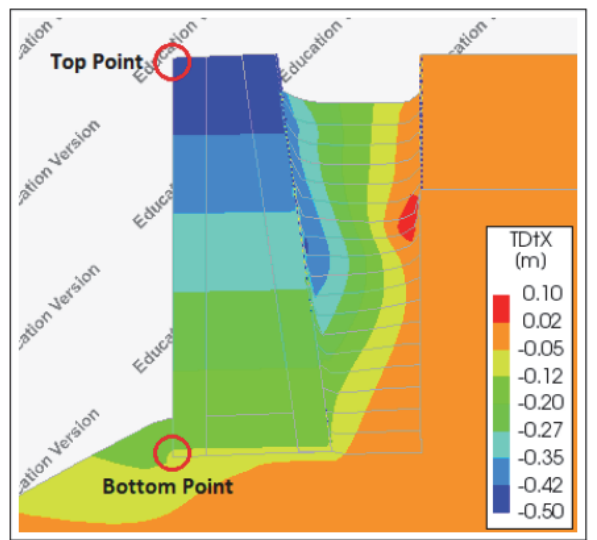

Figure 5: Control points for the capacity curves. [31]

\section{Results of the analysis in the as-built state}

In this paragraph the results of the analysis are represented as capacity curves, showing the hydraulic head - corresponding to the wall failure - against displacements (Fig. 6) with variable tensile strength. The diagrams show the curves for values of tensile strength from $1.25 \mathrm{kN} / \mathrm{m}^{2}$ to $12.50 \mathrm{kN} / \mathrm{m}^{2}$ and for two fracture energies: $G_{f}=0.00075 \mathrm{kN} / \mathrm{m}$ (Fig. $\left.6 \mathrm{a}\right)$ and $G_{f}=0.03$ $\mathrm{kN} / \mathrm{m}$ (Fig. 6 b). A monotonic trend is clearly visible, starting from a linear behavior up to values of hydraulic head of about $2 \mathrm{~m}$. Beyond this value, the trend is non-linear and the hydraulic head leading to collapse is asymptotically approaches 3.5 $\mathrm{m}$. This means that, even adopting higher (unrealistic) values of tensile strength for masonry, the critical water level cannot conceivably overcome such a value.

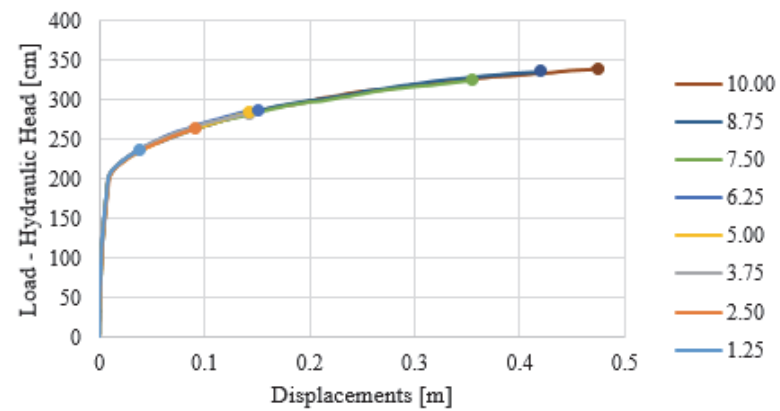

(a)

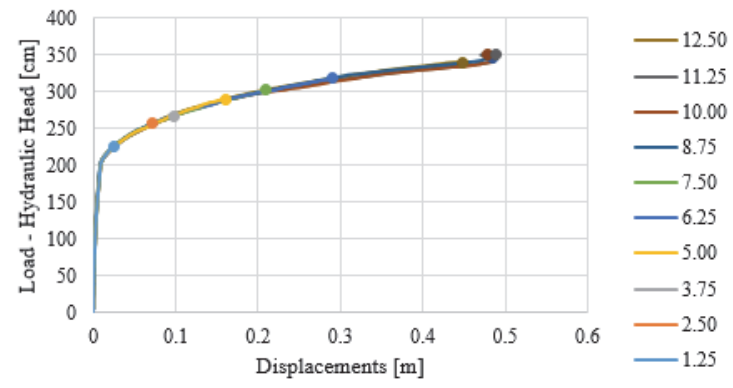

(b)

Figure 6: Capacity curves of the parametric analysis: variation of the tensile strength (in the legend, values in $\mathrm{kN} / \mathrm{m}^{2}$ ): $\mathrm{G}_{\mathrm{f}}=0.00075$ $\mathrm{kN} / \mathrm{m}$ (a) and $\mathrm{G}_{\mathrm{f}}=0.03 \mathrm{kN} / \mathrm{m}$ (b)

Investigating the failure pattern, a great difference in the propagation of the cracking is noticeable depending on the assumed values of strength:

- Case 1. For low values of tensile strength ( say $_{t}<f_{t . l i m}$ ), the wall starts to crack in its inner part due to the attainment of the tensile strength in the material. Once the inner core is reached, the cracks rapidly spread through it, given its low resistance. At this moment, only the external wall is able to provide support to the retaining wall, until the breakage propagates in its lower part, causing the collapse. This suggests that the collapse occurs due to the masonry material failure (tensile failure), caused by the stresses that develop in the structure under the imposed loads. The crack propagation pattern remains the same and spread to the external wall at the same height, included in a range of 1.5 to 
$2.5 \mathrm{~m}$ from the base level. This observation can result useful because it can make it possible to know which the most dangerous area is needed to be checked and monitored for possible interventions.

- Case 2. For higher values of tensile strength $f_{t}>f_{t}$.lim), in the initial phase the crack propagation is similar, but once the inner core is completely broken, the external wall resists in all its height. This time, however, the formation of a fracture line is not noticed. In this situation the wall collapses due to the sliding mechanism.

It is clear that the maximum displacement attained for the wall, of the order of some tenths of $\mathrm{cm}$, is not realistic, since local cracks can occur and propagate through the wall thickness. These aspects, part of the fracture mechanics, cannot be gathered from the model, where masonry is homogenized.

Observing what really happened during the actual retaining wall failure, it is possible to guess that case $1\left(\mathrm{f}_{\mathrm{t}}<\mathrm{f}_{\mathrm{t} . \mathrm{lim}}\right)$ is the one that took place. Indeed, after the collapse the lower part of the wall remained in place. The collapse mechanism probably was due to a slit that takes place in the lower part of the external wall face and that probably propagates inward following the material friction angle, according to a scheme very close to what is represented in Fig. 7. In practice the increasing of the horizontal action produces a partialisation of the resisting section with the progressive reduction of the compressed section. The only compressed section offer shear resistance and the collapse is obtained for the overcame of the shear resistance of this section section. It can be concluded that the maximum masonry tensile strength is around a value of $f_{t}=$ $15\left[\mathrm{kN} / \mathrm{m}^{2}\right]$.

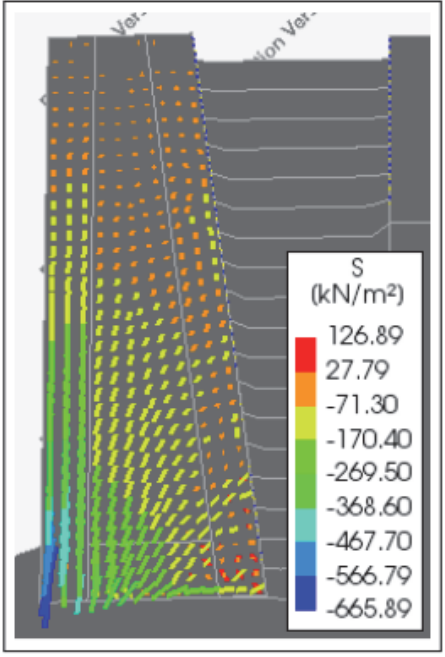

(a) Principal Stresses

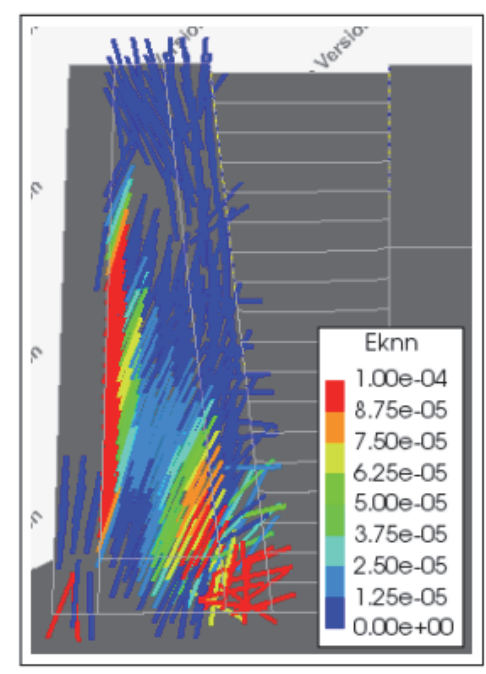

(b) Cracking Directions

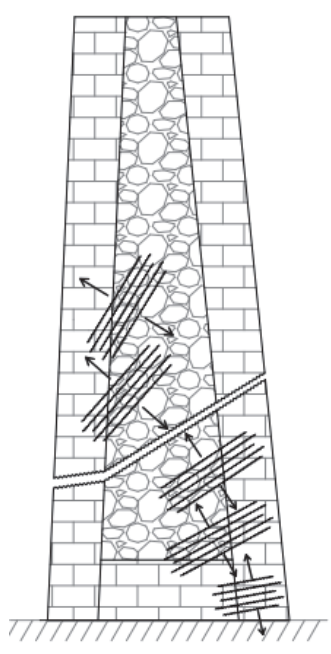

(c)

Figure 7: Stress distribution (a), corresponding cracking (b) and schematic view of the most likely collapse (c)

The non-linear static analysis carried out considers the only effect of the increase of hydrostatic head at the upstream section of the retaining wall. This is valuated considering a progressive growth of the thrust. The presence of moisture, particularly in a long-term scenario, also produce a degradation in the capacity both of masonry that on the soil [33]. This aspect is not considered in this work. The safety evaluation of the historical retaining wall have to be done considering the effects of drain obstruction. This is a recurring condition in the historical wall and can produce a sudden increase of the hydraulic action in case of rainstorm. In the case of Volterra is possible to notice a double origin of the hydraulic head. If from one hand the hydraulic head came from a loss of water of a sewer line that produce a slow saturation scenario, the occurrence of the severe rainstorm the day before the collapse had a crucial role in the collapse of Volterra.

In the common practical case that there is a clay or impermeable layer on the back of the wall, there can be an accumulation of water at a depth different from the foundation height. In this case the hydrostatic thrust has a greater lever arm and therefore a higher destabilizing moment with respect to the foundation. This can cause a different collapse mechanisms with crack in any cross section and therefore that aspect should be carefully considered. 


\section{ANALYSIS OF A RETROFITTED STATE}

$\mathrm{I}$ $\mathrm{t}$ is worthy to evaluate the role of a retrofitting solution that could have impeded the wall collapse [34,35]. A traditional but effective technique is adopted: a steel tie-rod installed at a certain depth in the sandy soil beyond the artificially added soil (Fig. 8 - a). The designed length is $9.3 \mathrm{~m}$ and the tie is modelled as a non-linear truss beam element (Fig. 8 b). The tensile force of the tie-rod is about $254 \mathrm{kN}$ if the design actions displayed in Fig. 9 are considered. The tie is so designed considered the limit equilibrium of the wall also in case of drain obstruction. The tie is placed in the half of the wall and the uplift pressure of the water is also take into account in the design of the tie. Assuming the high resistance steel ASTM A416, a minimum diameter of $15 \mathrm{~mm}$ results. In the numerical modelling, fracture energy, elastic modulus and compressive strength of the wall are kept constant, not being so significant for the capacity curves, whereas the diameter is the only variable parameter assumed.

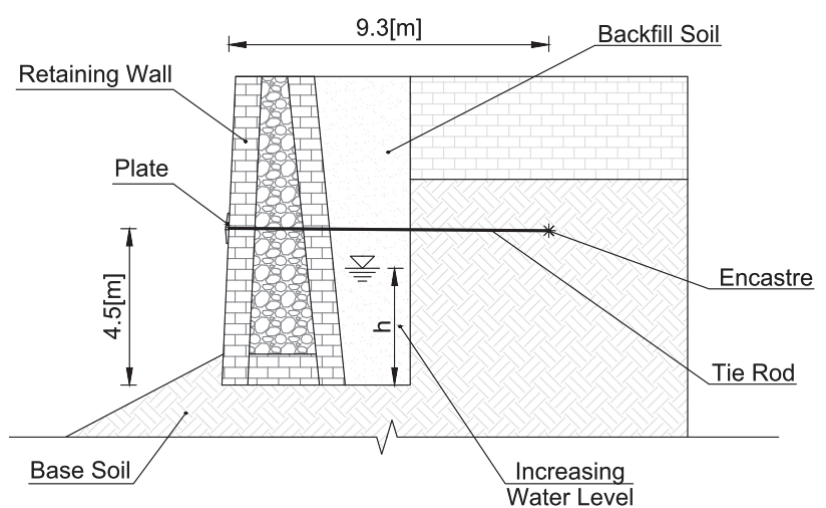

(a)

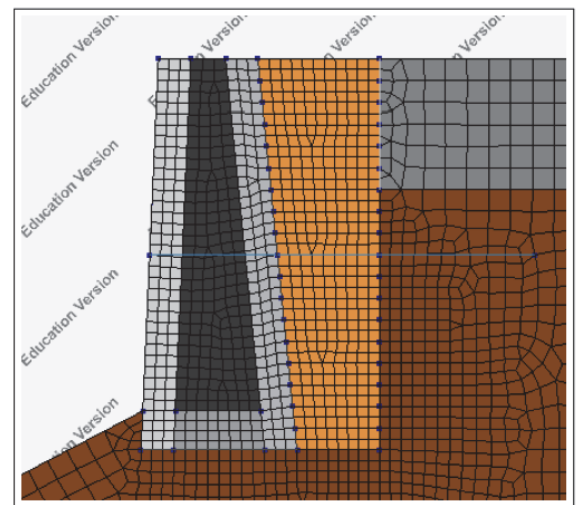

(b)

Figure 8: Retrofitting of the historic wall by means of a steel tie rod at mid-height (a) and analyzed finite element model (b).

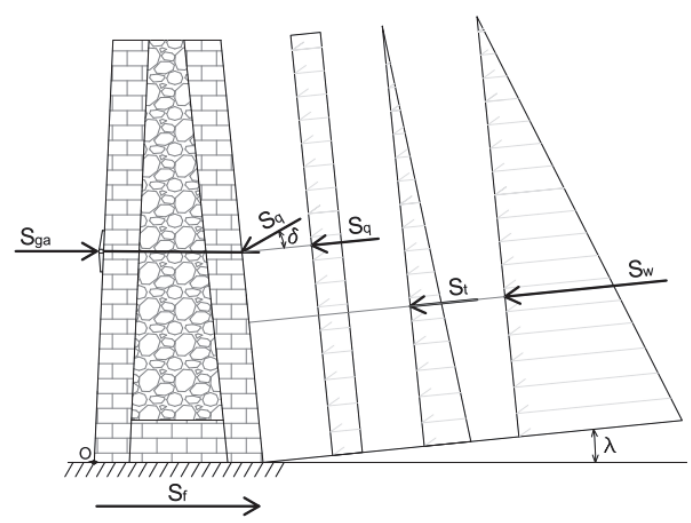

Figure 9: Actions acting on the retaining wall restrained by a tie-rod. [31]

The obtained results show a decisive increase in the water level necessary to cause the structural collapse. This improvement is due to the addition of a stabilizing force determining a beneficial effect for the internal stress distributions (Fig. $10 \mathrm{a}-\mathrm{b}$ ). As for a quantitative assessment, the tensile stress of the wall is one order of magnitude lower than that without tie-rod (Fig. 10 - a) whereas the compressive stress at the foot corner does not significantly change. The crack pattern is consequently improved as well with a reduced cracking in the inner part of the wall but a wider spread in the inner wall (Fig. 10 - c).

Another economic and effective solution is the restoration of the drain. This can be made by coring and it is recommended to produce alternate drainage both in height and in horizontal direction. This device is useful and recommendable even in the occurrence of a consolidation by means of tie elements. 


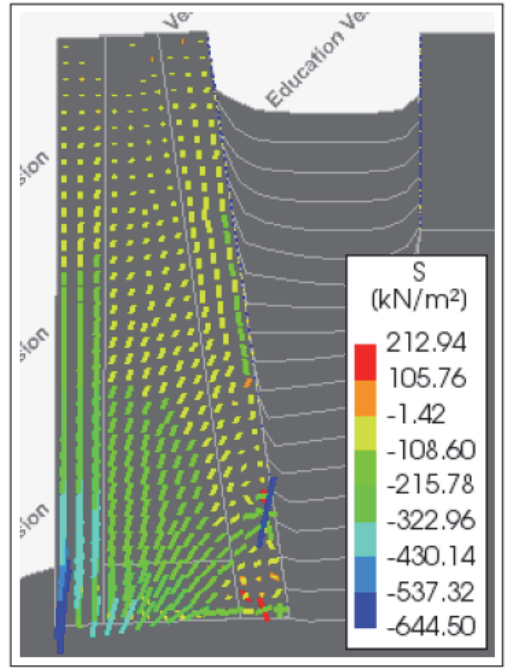

(a)

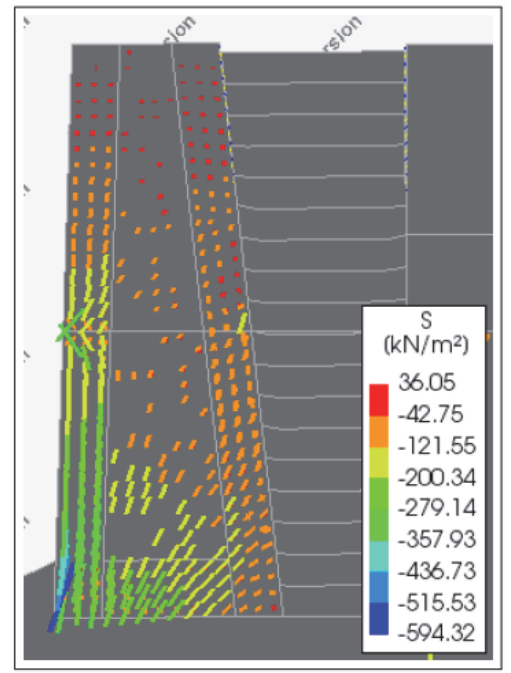

(b)

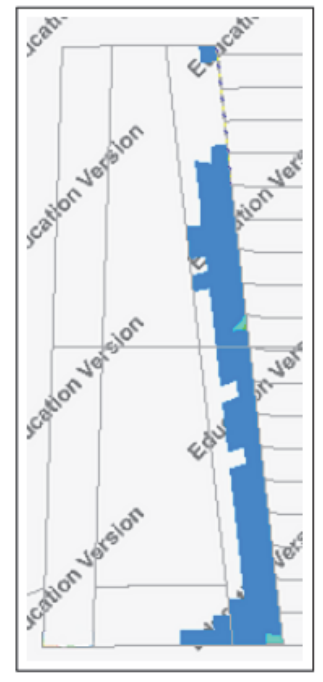

(c)

Figure 10: Principal stress distribution without (a) and with tie-rod (b); crack pattern with tie-rod (c).

\section{SIMPLIFIED ANALYSES IN THE 3-DIM MODEL}

$\mathrm{F}$ inally, the three-dimensional model was assessed, in order to verify the occurred "spoon shaped" section breakage. A stretch of wall with length 46 meters was considered since the collapsed portion of the wall is about $30 \mathrm{~m}$. By exploiting the symmetry of the problem, only half of it is modelled (Fig. 11). A careful modelling of the interface in contact with the adjacent portion of wall is necessary. It is chosen to model the constitutive law of the interface with a shear type non-linear behaviour by assuming a shear strength of 1.5 times the tensile strength (assumed equal to $10 \mathrm{kN} / \mathrm{m}^{2}$ ) and a tangential modulus 0.4 times the elastic modulus. The other parameters and boundary conditions are analogous to those assumed for the 2-dim model. The displacements and the cracking pattern matched with the actual one. Anyway the macroelement approach as simplified way to detect of the correctness of the results is commonly adopted in masonry constructions [36].

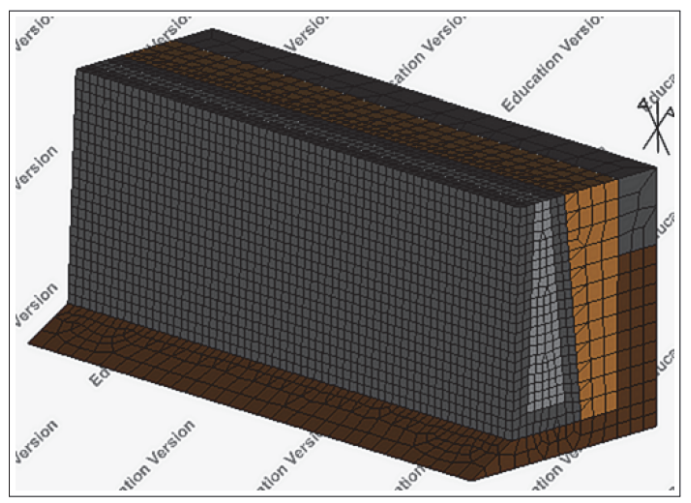

Figure 11: 3D model of the collapsed wall.

By increasing the water level and pushing the $3 \mathrm{~d}$ wall to collapse, it is possible to estimate the amount of out-of-plane displacement (Fig. 12 - a) and the cracking configuration (Fig. 12 - b), that is pretty similar to that actually occurred. The cracking pattern of the collapsed section of the 3 dim model is very similar to the one obtained by the 2-dim model of the 
collapsed section. This suggests that a fast investigation of the safety of the retaining wall can be done section by section, indagating the safety of several point with a 2-dim model.

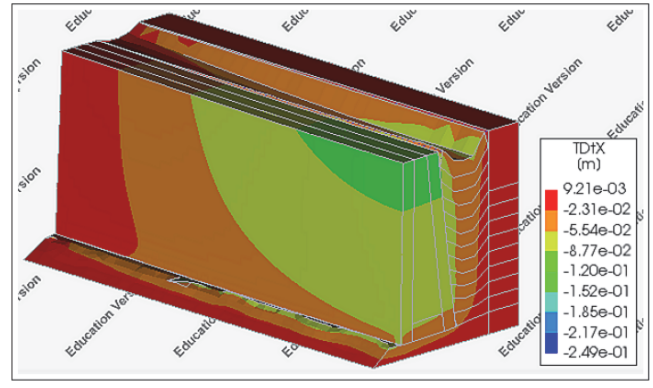

(a)

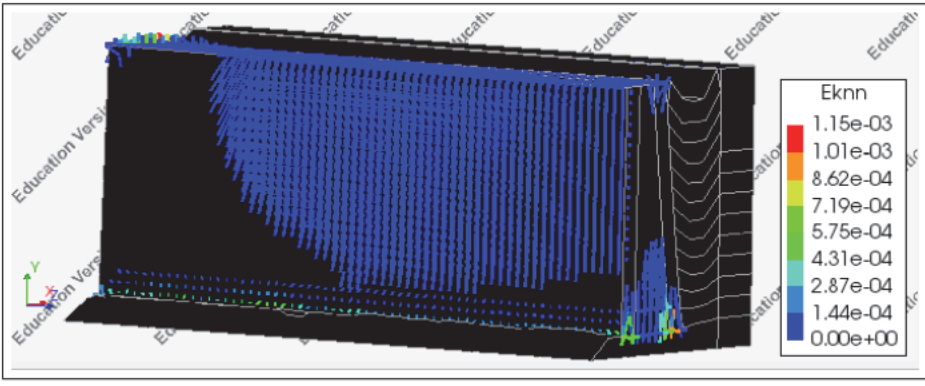

(b)

Figure 12: Out-of-plane displacements (a) and crack pattern (b) at collapse.

\section{CONCLUSIONS}

I $\mathrm{n}$ this paper the safety of the historical wall of Volterra is analyzed in order to evaluate the cause of the collapse occurred in 2014. Non-linear static analyses are carried out considering a growing hydrostatic head varying the fracture energy $G_{f}$ an the tensile strength $f_{t}$. Among all the considered parameters, only masonry tensile strength is demonstrated to play a crucial role for the assessment of the retaining wall. On the other hand, this parameter is difficult to evaluate, in particular for historical wall (with a significant thickness) and can have a significant variation section by section. Under the assumptions of an increasing groundwater level from the wall base, given the evidence of what observed after the actual collapse occurred (i.e. the wall base stayed in place), it is possible to consider that the failure took place according to the first mechanism case $\left(f_{t}<f_{t . l i m}\right)$. Hence, it was possible to trace the maximum masonry tensile strength, which does not exceed the value of $\mathrm{f}_{\mathrm{t}}=15 \mathrm{kN} / \mathrm{m}^{2}$. This value can help in any subsequent safety analysis to be carried out in the remaining medieval urban walls, as they were built in the same period.

Cracking path and displacement fields have been analyzed in order to evaluate the more likely failure mechanism and to propose retrofitting strategies. The effectiveness of a sub-horizontal tie placed in the middle of the wall, together with the installation of new drains, was also discussed. This intervention produced a significant increasing of the capacity of the wall in particular towards equilibrium but also in terms of resistance.

\section{ACKNOWLEDGEMENT}

he Authors thank the Municipality of Volterra, Prof. Mauro Sassu and Dr. Giorgia Giardina for the support in obtaining information about the case study and modelling, and Gianmarco Passera for developing part of the numerical models. The Authors also cite the MICHe (Mitigation of the Impact of natural hazard on Cultural

Heritage) project for the financial support.

\section{REFERENCES}

[1] Alecci, V., De Stefano, M., Focacci, F., Luciano, R., Rovero, L., Stipo, G. (2017). Strengthening Masonry Arches with Lime-Based Mortar Composite, Buildings, 7(2), pp. 49, DOI: 10.3390/buildings7020049.

[2] Alecci, V., Focacci, F., Rovero, L., Stipo, G., Stefano, M. De. (2017). Intrados strengthening of brick masonry arches with different FRCM composites: Experimental and analytical investigations, Compos. Struct., 176, pp. 898-909, DOI: https://DOI.org/10.1016/j.compstruct.2017.06.023.

[3] C. Casapulla; L. U. Argiento. (n.d.). In-plane frictional resistances in dry block masonry walls and rocking-sliding failure modes revisited and experimentally validated. 
[4] Casapulla, C., Giresini, L., Sassu, M., Lourenço, P.B. (2017). Rocking and kinematic approaches of masonry walls: state of the art and recent developments, Buildings, DOI: 10.3390/buildings7030069.

[5] Casapulla, C., Argiento, L.U. (2016). The comparative role of friction in local out-of-plane mechanisms of masonry buildings. Pushover analysis and experimental investigation, Eng. Struct., 126, pp. 158-173, DOI: $10.1016 /$ j.engstruct.2016.07.036.

[6] Giresini, L. (2016). Energy-based method for identifying vulnerable macro-elements in historic masonry churches, Bull. Earthq. Eng., 14(3), pp. 919-942, DOI: 10.1007/s10518-015-9854-7.

[7] Giresini, L., Sassu, M., Butenweg, C., Alecci, V., De Stefano, M. (2017). Vault macro-element with equivalent trusses in global seismic analyses, Earthq. Struct., 12(4), pp. 409-423, DOI: 10.12989/eas.2017.12.4.409.

[8] Andreini, M., De Falco, A., Giresini, L., Sassu, M. (2014). Mechanical characterization of masonry walls with chaotic texture: procedures and results of in-situ tests, Int. J. Archit. Herit. Conserv. Anal. Restor., 8(3), pp. 376-407, DOI: $10.1080 / 15583058.2013 .826302$.

[9] Giresini, L. (2017).Design strategy for the rocking stability of horizontally restrained masonry walls. In: M. Papadrakakis, M.F., (Ed.), COMPDYN 2017 6th ECCOMAS Thematic Conference on Computational Methods in Structural Dynamics and Earthquake Engineering, Rhodes Island, Greece.

[10] Chan, Y. (1996). Study of old masonry retaining walls in Hong Kong, , GEO REPORT 31, Geotechnical Engineering Office, Civil Engineering Department, Hong Kong.

[11] Andreini, M., De Falco, A., Giresini, L., Sassu, M. (2013). Collapse of the historic city walls of Pistoia (Italy): Causes and possible interventions, Appl. Mech. Mater., 351-352.

[12] Madiai, C., Facciorusso, J., Gargini, E. (2017). Numerical modeling of seismic site effects in a shallow alluvial basin of the Northern Apennines (Italy), Bull. Seismol. Soc. Am., 107(5), pp. 2094-2105, DOI: 10.1785/0120160293.

[13] Casapulla, C., Argiento, L.U., Maione, A. (2018). Seismic safety assessment of a masonry building according to Italian Guidelines on Cultural Heritage: simplified mechanical-based approach and pushover analysis, Bull. Earthq. Eng.,

[14] DOI: 10.1007/s10518-017-0281-9.

[15] Sassu, M., Andreini, M., Casapulla, C., De Falco, A. (2013). Archaeological consolidation of UNESCO masonry structures in Oman: The sumhuram citadel of Khor Rori and the Al Balid Fortress, Int. J. Archit. Herit., 7(4), pp. 339374, DOI: $10.1080 / 15583058.2012 .665146$.

[16] Sassu, M., Stochino, F., Mistretta, F. (2017). Assessment method for combine structural and energy retrofitting in masonry buildings, Buildings, 7(71).

[17] Szalwinski, C.M. (2017). On critical states, rupture states and interlocking strength of granular materials, Materials (Basel)., 10(8), DOI: 10.3390/ma10080865.

[18] Swan, C.C., Seo, Y.K. (1999). Limit state analysis of earthen slopes using dual continuum/fem approaches, Int. J. Numer. Anal. Methods Geomech., 23(12), pp. 1359-1371, DOI: 10.1002/(SICI)1096-9853(199910)23:12<1359::AIDNAG39>3.0.CO;2-Y.

[19] Amoroso, S., Milana, G., Rollins, K., Comina, C., Minarelli, L., Manuel, M., Monaco, P., Franceschini, M., Anzidei, M., Lusvardi, C., Cantore, L., Carpena, A., Casadei, S., Cinti, F., Civico, R., Cox, B., De Martini, P., Di Giulio, G., Di Naccio, D., Di Stefano, G., Facciorusso, J., Famiani, D., Fiorelli, F., Fontana, D., Foti, S., Madiai, C., Marangoni, V., Marchetti, D., Marchetti, S., Martelli, L., Mariotti, M., Muscolino, E., Pancaldi, D., Pantosti, D., Passeri, F., Pesci, A., Romeo, G., Sapia, V., Smedile, A., Stefani, M., Tarabusi, G., Teza, G., Vassallo, M., Villani, F. (2018). The first Italian blast-induced liquefaction test (Mirabello, Emilia-Romagna, Italy): description of the experiment and preliminary results, Ann. Geophys. Geophys., 60(5), DOI: 10.4401/ag-7415.

[20] Li, T., Atamturktur, S. (2014). Fidelity and Robustness of Detailed Micromodeling, Simplified Micromodeling, and Macromodeling Techniques for a Masonry Dome, J. Perform. Constr. Facil., 28(3), pp. 480-490,

DOI: 10.1061/(ASCE)CF.1943-5509.0000440.

[21] Taddei, F., Reindl, L., Park, J., Butenweg, C., Karadogan, F. (2011). Numerical investigation of AAC wall panels based on the damage plasticity constitutive law, Cem. Wapno, Bet., (SPEC.ISSUE), pp. 86-91.

[22] Lewicki, B. (1992). Research problems connected with masonry multileaves external walls, CIB Rep., , pp. 119-119.

[23] Fernandez, F. (n.d.). Caratterizzazione del materiale lapideo finalizzata all'individuazione dei requisiti delle malte da adoperare per il ripristino delle strutture murarie.

[24] Fernandez, F. (2019).A study of collapse in slopes using MPM and NLA (Numerical Limit Analysis). 2nd International Conference on the Material Point Method for Modelling Soil-Water-Structure Interaction, pp. 323-330.

[25] Lourenço, P.B., Rots, J.G., Blaawendraad, J. (1998). Continuum model for masonry: parameter estimation and validation, J. Struct. Eng., 124(6), pp. 642-652. 
[26] (2018). DIANA FEA, Finite Element software package, Delft, The Netherlands.

[27] Manie, J. (2017). Diana FEA manuals. DIANA FEA BV Delftechpark 19a, 2628 XJ Delft, The Netherlands.

[28] Lourenço, P.B. (2002). Computations on historic masonry structures, Prog. Struct. Eng. Mater., 4(3), pp. 301-319.

[29] Reinhardt, H.W. (1984). Fracture Mechanics of an Elastic Softening Material like Concrete, HERON, 29(2), pp. 3-42.

[30] Lourenço, P.B., De Borst, R., Rots, J.G. (1997). A plane stress softening plasticity model for orthotropic materials, Int. J. Numer. Methods Eng., 40(21), pp. 4033-4057.

[31] Angelim, R.R., Cunha, R.P., Sales, M.M. (2016).Determining the Elastic Deformation Modulus From a Compacted Earth Embankment Via Laboratory and Ménard Pressuremeter Tests. Soils and Rocks, São Paulo, 39(3), pp. 285-300.

[32] Passera, G. (2018).Numerical Analysis of a Masonry Retaining Wall: The Case of Volterra's Urban Walls. Università di Pisa, Univerisity of Bath.

[33] Fletcher, R. (1987). Practical methods of optimization, New York.

[34] Schilirò, L., Montrasio, L., Scarascia Mugnozza, G. (2016). Prediction of shallow landslide occurrence: Validation of a physically-based approach through a real case study, Sci. Total Environ., 569-570, pp. 134-44, DOI: $10.1016 /$ j.scitotenv.2016.06.124.

[35] Mistretta, F., Stochino, F., Sassu, M. (2019). Structural and thermal retrofitting of masonry walls: An integrated costanalysis approach for the Italian context, Build. Environ., 155, pp. 127-136.

[36] Tattoni, S., Stochino, F. (2013). Collapse of prestressed reinforced concrete jetties: durability and faults analysis, Case Stud. Eng. Fail. Anal., 1, pp. 131-138.

[37] Pantò, B., Giresini, L., Sassu, M., Calliò, I. (2017). Non-linear modeling of masonry churches through a discrete macroelement approach, Earthquake and Structures, Earthq. Struct., 12(2), pp. 223-236. 